\title{
The management of mixed urinary incontinence in women
}

\author{
Blayne Welk, $M D^{1}$; Richard J. Baverstock, $M D^{2}$
}

'Department of Surgery, Western University, London, ON; ${ }^{2}$ vesia [Alberta Bladder Centre] and Department of Surgery, University of Calgary, Calgary, AB; Canada

Cite as: Can Urol Assoc J 2017;11 (6Suppl2):S121-4. http://dx.doi.org/10.5489/cuaj.4584

\section{Abstract}

Mixed urinary incontinence is a common diagnosis among women with urinary leakage and is often present in women who are unable to characterize their incontinence. Research and optimized clinical treatment of these patients is limited by the challenges in objectively defining and stratifying this population. The evaluation of these patients should follow the same general principles as any assessment of any women with incontinence; however, it is essential to define whether urge or stress incontinence is the predominant symptom. Urodynamics (UDS) may be helpful in this regard and may help predict surgical outcomes. Behavioural therapy, weight loss, and pelvic floor muscle therapy are usually appropriate initial management strategies. In postmenopausal women, vaginal estrogen can be considered, and in women with equal parts stress and urge incontinence or urge-predominant mixed incontinence, a trial of anticholinergics or beta-3 agonists is appropriate. In women with stress-predominant or equal parts stress and urge incontinence, stress incontinence surgery can be considered, with the caveat that outcomes are generally worse among women with more severe levels of urgency, success rates may not be as durable, and a significant proportion of women may need additional medical therapy.

\section{Introduction}

Mixed urinary incontinence is defined as involuntary urine loss associated with both physical exertion/increased intraabdominal pressure and with urinary urgency. It is estimated that one in three women with incontinence have mixed incontinence. ${ }^{1}$ It seems to be more common in older women and it has a greater impact on a woman's quality of life compared to pure urgency or stress incontinence. ${ }^{2}$ The etiology of mixed incontinence may be due to two independent pathologies (bladder dysfunction and an incompetent urethral sphincter mechanism), or due primarily to an incompetent sphincter, which allows urine into the proximal urethral, causing both traditional stress incontinence at times, as well as reflexive detrusor contractions and urgency incontinence. ${ }^{3,4} \mathrm{~A}$ recent study of women with mixed urinary incontinence who completing a 30-day enhanced bladder diary found that stress-induced urgency incontinence was actually the most common pattern seen among their incontinence episodes. ${ }^{5}$ The study and characterization of mixed urinary incontinence is challenging due to intermingling of multiple patient phenotypes (made up of varying combinations of stress incontinence, detrusor overactivity [DO], and sensory urgency ${ }^{6}$ ), and the inclusion of women with pure stress incontinence who react to their stress incontinence with urgent voiding. ${ }^{7}$

\section{Clinical evaluation}

The evaluation of women with mixed incontinence should follow the same general principles as outlined in the Canadian Urological Association (CUA) guidelines for incontinence, ${ }^{8}$ with an overview of storage and voiding symptoms; general urological symptoms, such as urinary infections, pelvic pain, and hematuria; and a relevant review of systems, which includes questions about bowel function, neurological symptoms, prolapse symptoms, fluid intake, prior urological/gynecological surgery, and pelvic radiation. The most important addition to the history is the need to characterize whether the mixed incontinence is stress-predominant or urge-predominant. A useful tip is to ask the patient to finish the sentence: "I leak the most when I...?" This will determine whether to pursue a treatment paradigm based primarily on overactive bladder (OAB) or stress incontinence (Fig. 1). The approach of treating the predominant symptom has been validated by studies showing good concordance between the dominant type of incontinence and urodynamic findings. ${ }^{9}$ Determining which type of incontinence appeared first may also be important, as some studies have suggested that women with stress incontinence symptoms predating urgency symptoms will have greater success with surgical intervention. ${ }^{10}$ While there is no gold standard method to determine if a patient has stress- or urge-predominant incontinence, validated questionnaires have been developed to try and quantify the dominant diagnosis, and often, voiding diaries are helpful 


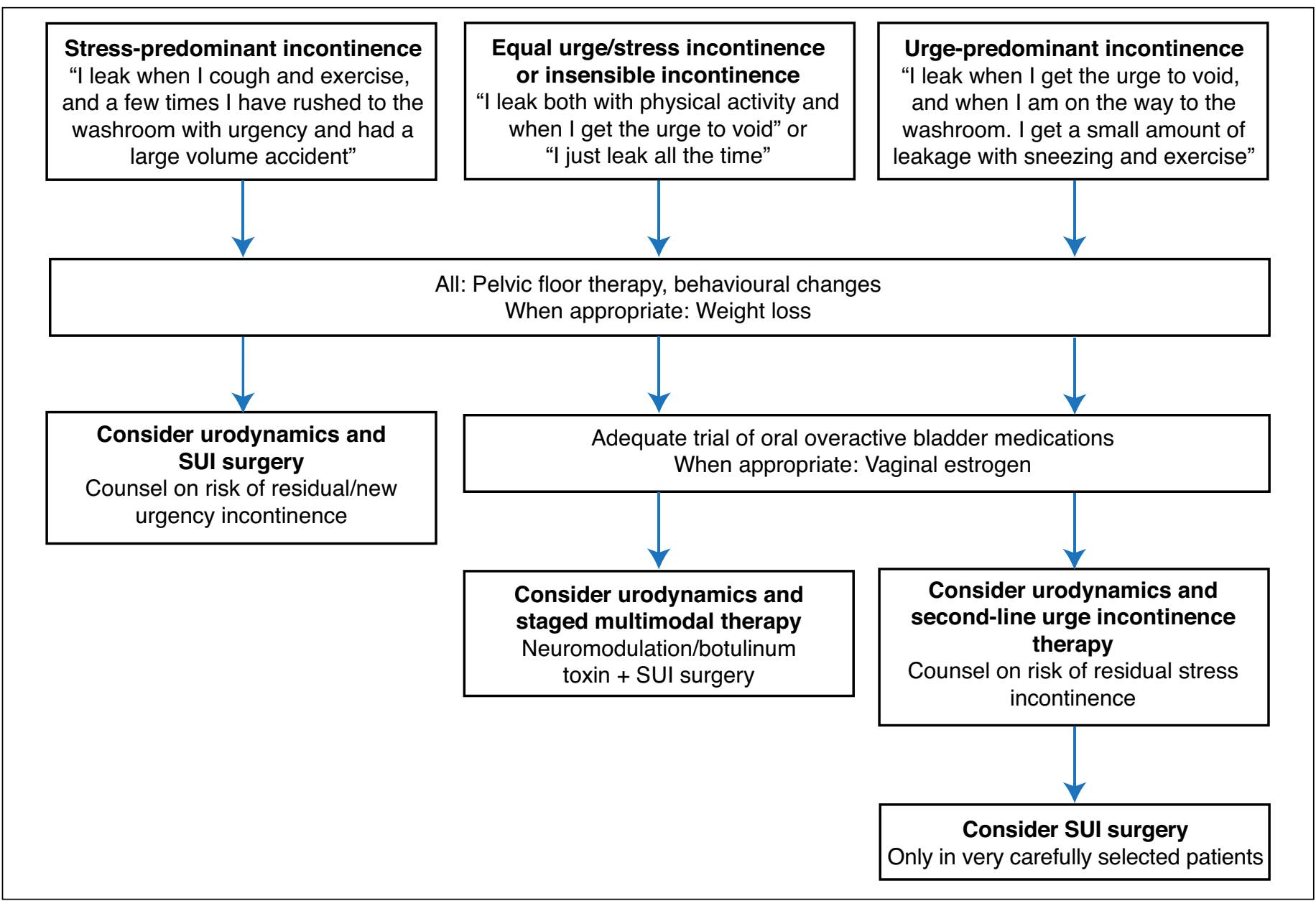

Fig. 1. Incontinence treatment paradigm. SUI: stress urinary incontinence.

to document the type of incontinence. ${ }^{11}$ The patient reported International Consultation on Incontinence QuestionnaireUrinary Incontinence (ICIQ-UI) provides a rapid and easily interpretable way to assess the type of incontinence. ${ }^{12}$ Patients with "insensible incontinence" (meaning it is not obviously related to urgency or stress activities) are challenging to treat, and even UDS do not always offer an answer. ${ }^{13}$

On examination of the patient, significant obesity should be noted, and an abdominal exam, screening neurological exam, and pelvic exam (to identify significant pelvic organ prolapse, pelvic floor function, objective stress incontinence, and vaginal atrophy) should be performed. If a woman has a positive cough test, followed a few seconds later by sudden urgency and large volume incontinence, this may represent stress induced $\mathrm{DO}$, and a trial of $\mathrm{OAB}$ therapy may significant improve their symptoms. Urinalysis and postvoid residual urine measurement are recommended initial investigations to identify infection, hematuria, and poor bladder emptying. In cases where more invasive therapy is being considered, UDS may play a beneficial role in patient counselling and pre-intervention physician confidence. The American Urologic Association (AUA) guidelines on UDS state that "in the setting of mixed urinary incontinence, UDS may contribute by aiding in symptom correlation. However, these tests may not precisely predict outcomes of treatment." ${ }^{14}$ The exact parameters that predict surgical success are debatable; however, studies have generally suggested that among women with mixed incontinence, patients with DO (particularly when high pressure or at early filling volumes) and a low urodynamic capacity have higher failure rates after SUI surgery. ${ }^{3,15}$ The utility of UDS is limited by a poor sensitivity for detection of DO (compared to ambulatory UDS), and the contradictory results of some studies which suggest that patients with DO are more likely to have resolution of their urgency symptoms..$^{10,16}$

\section{Non-surgical treatment}

The initial conservative management for any women with mixed incontinence is similar, and includes weight loss, 
behaviour modification, pelvic floor muscle training (PFMT), reduced fluid intake, and caffeine moderation. ${ }^{11}$ The evidence for PFMT is limited for mixed incontinence; nevertheless, a recent systematic review found that women treated with PMFT (for at least three months) are significantly more likely to have improvement or complete resolution of their urinary incontinence, even with mixed incontinence. ${ }^{17}$ It is important to note that PFMT is still an appropriate first-line therapy in women with urge predominant mixed incontinence, although it is more likely for the stress incontinence component to resolve. While systemic estrogen supplement is not associated with an improvement in incontinence (and perhaps even worsens symptoms), topical vaginal estrogen has been generally shown to decrease urinary urgency, frequency, and nocturia in postmenopausal women. ${ }^{18}$ It has not been well-evaluated specifically for mixed incontinence.

Given the potential harm associated with surgical intervention, it makes sense to first consider a trial of medical therapy for women with urge predominant mixed urinary incontinence or in women who are unable to identify a predominant type of incontinence. While an attempt was made to conduct a randomized clinical trial evaluating initial $\mathrm{OAB}$ therapy or surgical therapy, the trial failed to recruit patients, so there is no high-level evidence supporting this approach. ${ }^{2}$ However, secondary analysis of pooled, randomized, placebo-controlled trials for OAB have demonstrated that a significant proportion of women with urge predominant mixed urinary incontinence have complete resolution of their incontinence. ${ }^{19}$ This suggests that either these patients were incorrectly classified as mixed incontinence (despite the rigorous assessment that goes along with a clinical trial), or that the etiology of the stress incontinence component of some women's mixed symptoms responds to anticholinergic therapy (for example, the case of stress induced DO). In the setting of urge predominant mixed urinary incontinence, a clinical trial randomized women to either tolterodine or placebo, and found that the resolution of the $O A B$ symptoms followed the pattern seen in traditional OAB populations. ${ }^{20}$ Other medical options include the off-label use of imipramine (a tricyclic antidepressant) or duloxetine (a serotonin and norepinephrine reuptake inhibitor). ${ }^{2}$ Likely the results of anticholinergic therapy in this population can be applied to beta-3 agonists.

\section{Surgical treatment}

SUI procedures are generally indicated for women with stress-predominant mixed urinary incontinence or in carefully evaluated women with equal components of stress and urgency incontinence. The surgical treatment for these women could include urethral bulking agents, retropubic suspensions, bladder neck slings, or midurethral slings. However, as the vast majority of incontinence procedures in contemporary practice consist of midurethral slings, this is the most relevant surgical procedure to discuss. ${ }^{21}$

A systematic review and meta-analysis of midurethral slings in women with mixed urinary incontinence calculated a rather sobering overall subjective incontinence cure rate of $56 \%$ among women with a mean followup of approximately three years. ${ }^{22}$ Overall success rates after midurethral slings are intuitively related to the degree of urgency incontinence (approximately $50 \%$ for urge predominant, $60 \%$ for equal mixed incontinence, and $80 \%$ for stress predominance), and just as in women with stress incontinence, the subjective success rates decline with time. ${ }^{11}$ This "recurrent incontinence" may be more pronounced and rapid than among women with pure stress incontinence. ${ }^{4} \mathrm{~A}$ secondary analysis of a large randomized clinical study of Burch colposuspension vs. autologous fascial pubovaginal sling demonstrated a robust dose-response relationship between a validated urgency score and overall surgical failure. ${ }^{3}$ Although reported rates of resolution of the urgency incontinence and $O A B$ symptoms are generally high after SUI surgery in women with stress-predominant mixed incontinence (approximately $60 \%$ ), the durability of this improvement may be limited. ${ }^{23}$ In women with significant pelvic organ prolapse, consideration may be given to a combined SUI and prolapse procedure, as this may lead to a greater likelihood of complete resolution of the mixed incontinence. ${ }^{1}$ Some studies have suggested that a transobturator midurethral sling is more likely to lead to complete resolution of the mixed incontinence, perhaps owing to the less obstructive nature of this approach; ${ }^{1,3}$ however, a meta-analysis of randomized trials in women with mixed incontinence demonstrated no significant difference in outcomes. ${ }^{22}$ Worsening urgency and urge incontinence after a SUI procedure should lead to a careful reassessment of the patient. Urine culture, cystoscopy to assess for urethral/bladder foreign bodies, and UDS to assess for bladder outlet obstruction should be performed and used to direct treatment. In women with none of these complications, additional therapy in the form of OAB medications, intravesical botulinum toxin, or neuromodulation is appropriate. In women with significant onset of symptoms after a midurethral sling procedure, consideration can be given to sling division; however, there is a $20-50 \%$ risk of recurrent stress incontinence. ${ }^{24}$

\section{Conclusion}

Defining which women have true mixed urinary incontinence can be challenging. At the initial visit, counselling around behaviour modifications and PFMT is appropriate. The efficacy of PFMT is related to the intensity of the training program, and level of involvement of experienced PFMT physiotherapists or nurses; it is appropriate for all types of mixed incontinence. Vaginal estrogen is a low-risk 
Welk et al.

therapy that can be considered in postmenopausal women. As medical therapy for $O A B$ can be easily discontinued if women experience side effects or lack of efficacy, it is a logical consideration for women with mixed incontinence, although efficacy is quite low among those with a strong stress-predominant incontinence history.

General principles when considering SUI surgery in women with mixed urinary incontinence include:

1. Documentation of a positive cough test (to ensure there is a definite component of stress incontinence).

2. Determining whether preoperative UDS will change your decision to offer surgery, or change the patient's decision to go ahead with surgery.

3. Proper counselling is essential to ensure the patient understands the goals of surgery. The patient needs to clearly understand the surgical procedure is designed to treat the stress component and that they may need further treatment for urgency incontinence post-operatively.

4. When offering surgical therapy, it is important to remember that in patients with mixed incontinence, satisfaction after a midurethral sling is highly related to the improvement in the urgency and urge incontinence. ${ }^{25}$

Competing interests: Dr. Welk has received investigator-initiated funding from Astellas. Dr. Baverstock reports no competing personal or financial interests relevant to this review.

This paper has been peer reviewed.

\section{References}

1. Gomelsky A, Dmochowski RR. Treatment of mixed urinary incontinence in women. Curr Opin Obstet Gynecol 2011;23:371-5. https://doi.org/10.1097/GC0.0b013e32834a9298

2. Lee EW, Kobashi KC. Mixed incontinence: What takes precedence in its management? Curr Urol Rep 2014;15:461. htrps://doi.org/10.1007/s1 1934-014-0461-y

3. Brucker BM. Expectations of stress urinary incontinence surgery in patients with mixed urinary incontinence. Rev Urol 2015;17:14-19.

4. Chughtai B, Laor L, Dunphy C, et al. Diagnosis, evaluation, and treatment of mixed urinary incontinence in women. Rev Urol 2015;17:78-83.

5. Minassian VA, Yan XS, Pitcavage J, et al. Mixed incontinence masked as stress-induced urgency urinary incontinence. J Urol 2016;196:1190-5. https://doi.org/10.1016/i.juro.2016.04.084

6. Tyagi R, Staskin DR. Mixed incontinence: The misclassification of patients and limitations of clinical trials. Curr Bladder Dysfunct Rep 2006;1:35-9. https://doi.org/10.1007/s1 1884-006-0005-5
7. Chou EC-L, Blaivas JG, Chou L-W, et al. Urodynamic characteristics of mixed urinary incontinence and idiopathic urge urinary incontinence. Neurourol Urodyn 2008;27:376-8. https://doi.org/10.1002/ nau.20536

8. Bettez M, Tu LM, Carlson K, et al. 2012 update: Guidelines for adult urinary incontinence collaborative consensus document for the Canadian Urological Association. Can Urol Assoc J 2012;6:354-63. https://doi.org/10.5489/cuaj.12248

9. Digesu GA, Salvatore $S$, Fernando R, et al. Mixed urinary symptoms: what are the urodynamic findings? Neurourol Urodyn 2008;27:372-5. https://doi.org/10.1002/nau.20530

10. Chaliha C, Khullar V. Mixed incontinence. Urology 2004;63(3Suppl1):51-7. https://doi.org/10.1016/i. urology.2004.01.015

11. Myers DL. Female mixed urinary incontinence: A clinical review. JAMA 2014;311:2007-14. https://doi.org/10.1001/jama.2014.4299

12. Avery K, Donovan J, Peters TJ, et al. ICIQ: A brief and robust measure for evaluating the symptoms and impact of urinary incontinence. Neurourol Urodyn 2004;23:322-30. https://doi.org/10.1002/ nau.20041

13. Brucker $B M$, Fong $E$, Kaefer $D$, et al. Urodynamic findings in women with insensible incontinence. Int J Urol 2013;20:429-33. https://doi.org/10.1111/.1.1442-2042.2012.03146.x

14. Winters JC, Dmochowski RR, Goldman HB, et al. Urodynamic studies in adults: AUA/SUFU guideline. J Urol 2012;188(6 Suppl):2464-72. https://doi.org/10.1016/i.juro.2012.09.081

15. Katsumi HK, Rutman MP. Can we predict if overactive bladder symptoms will resolve after sling surgery in women with mixed urinary incontinence? Curr Urol Rep 2010;11:328-37. https://doi.org/10.1007/ s1 1934-010-0133-5

16. Choe JH, Choo M-S, Lee K-S. The impact of tension-free vaginal tape on overactive bladder symptoms in women with stress urinary incontinence: Significance of detrusor overactivity. J Urol 2008;179:214-9. https://doi.org/10.1016/i.juro.2007.08.151

17. Dumoulin C, Hay-Smith J, Mac Habée-Séguin G, et al. Pelvic floor muscle training vs. no treatment, or inactive control treatments, for urinary incontinence in women: A short-version Cochrane systematic review with meta-analysis. Neurourol Urodyn 2015;34:300-8. https://doi.org/10.1002/nau.22700

18. Weber MA, Kleijn $M H$, Langendam $M$, et al. Local oestrogen for pelvic floor disorders: A systematic review. PLoS ONE 2015;10:e0136265-e0136265. https://doi.org/10.1371/journal.pone.0136265

19. Staskin DR, Te AE. Short- and long-term efficacy of solifenacin treatment in patients with symptoms of mixed urinary incontinence. BJU Int 2006;97:1256-61. https://doi.org/10.1111/j.1464410X.2006.06150.x

20. Khullar V, Hill S, Laval K-U, et al. Treatment of urge-predominant mixed urinary incontinence with tolterodine extended release: A randomized, placebo-controlled trial. Urology 2004;64:269-74; discussion 274-5. https://doi.org/10.1016/j.urology.2004.02.029

21. Dmochowski RR, Blaivas JM, Gormley EA, et al. Update of AUA guideline on the surgical management of female stress urinary incontinence. J Urol 2010;183:1906-14. https://doi.org/10.1016/i. juro.2010.02.2369

22. Jain $P$, Jirschele $K$, Botros $S M$, et al. Effectiveness of midurethral slings in mixed urinary incontinence: $A$ systematic review and meta-analysis. Int Urogynecol J 2011;22:923-32. https://doi.org/10.1007/ s00192-011-1406-3

23. Zyczynski HM, Albo ME, Goldman $H B$, et al. Change in overactive bladder symptoms after surgery for stress urinary incontinence in women. Obstet Gynecol 2015;126:423-30. https://doi.org/10.1097/ AOG.0000000000000929

24. Clifton MM, Linder BJ, Lightner DJ, et al. Risk of repeat anti-incontinence surgery following sling release: A review of 93 cases. J Urol 2014;191:710-4. https://doi.org/10.1016/i.juro.2013.09.030

25. Padmanabhan $P$, Panfili $Z$, Parker $W$, et al. Change in urinary storage symptoms following treatment for female stress urinary incontinence. Int Urogynecol J 2016;27:1169-74. https://doi.org/10.1007/ s00192-016-2951-6

Correspondence: Dr. Blayne Welk, Department of Surgery, Western University, London, ON, Canada; bkwelk@gmail.com 